\title{
The stowaways
}

\section{Over the coming decade, exploration of Mars may reveal whether or not life ever existed on the red planet — but only if the missions can avoid detecting any microbes they bring with them, says Tom Clarke.}

Pats n 1976, NASA's two Viking landers bumped down on the surface of Mars and began their search for life. They failed to find any, showing instead that the martian topsoil is extremely inhospitable - highly oxidizing and continually bombarded by massive doses of ultraviolet radiation.

After Viking, most scientists believed Mars to be lifeless. But the subsequent discovery of bacteria living in extreme Earthly environments, such as in Antarctic ice and the near-boiling, sulphurous waters of deep-sea hydrothermal vents, together with mounting evidence that water once flowed over the red planet, has rekindled hope that there could be - or at least could once have been - life on Mars.

Now NASA and the European Space Agency (ESA) are set to embark on a series of new missions to Mars. But a lingering problem remains - how to ensure that the landers' highly sensitive life-detection instruments are not fooled by biological molecules that have hitched a ride from Earth. Kenneth Nealson, an astrobiologist at the California Institute of Technology in Pasadena, says the field is haunted by the possibility of a humiliating embarrassment that it would never live down: “Thinking you've detected life on Mars and finding that it's Escherichia coli from Pasadena."

Before Viking, fears that terrestrial life could contaminate other planets meant that techniques for sterilizing spacecraft were given high priority. But once Viking showed that Mars is almost certainly incapable of supporting life from Earth, the issue slipped down the agenda. "Current technologies are basically the same as they were in the sixties and seventies," says Bob Koukol of NASA's planetary protection group, based at the Jet Propulsion Laboratory in Pasadena.

Worried about the potential for false positives in their search for martian life, both NASA and ESA are experimenting with a range of new anti-contamination techniques. Neither agency has time to spare. ESA's Mars Express mission includes Beagle 2, a John Rummel: cleaning is the big challenge.

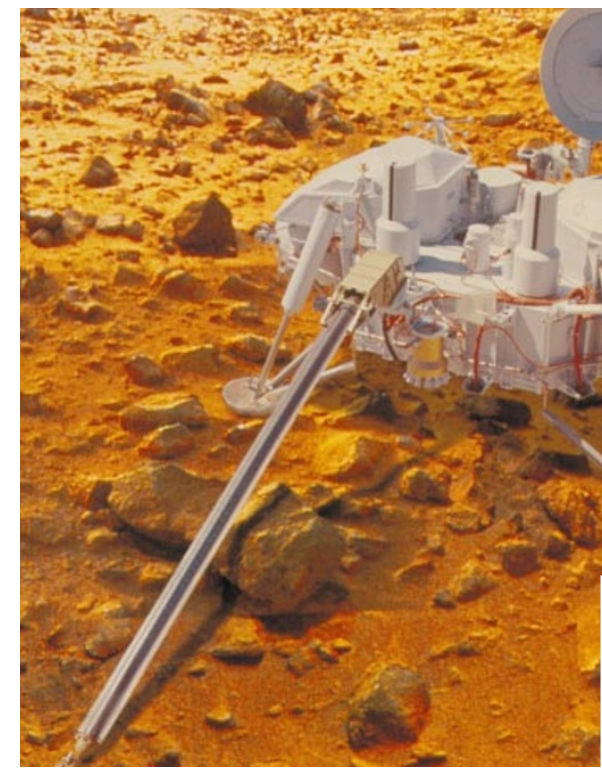

Sterilizing technology in the facilities where spacecraft are assembled (right) has changed little since Viking's mission to Mars in the 1970s.

Mars Express should launch in mid-2003 and arrive later the same year. NASA plans to land a clutch of rovers on the planet in 2004, followed by further missions in 2007.

\section{Viking invaders}

Researchers involved in the search for new methods to sterilize spacecraft face several difficulties. Traditional techniques - the Viking probes were sterilized by heating to around $100{ }^{\circ} \mathrm{C}$ for 30 hours - are not applicable to modern spacecraft with their fragile microprocessors and composite materials. And although spores of at least one type of bacterium were known to have survived Viking's heat treatment, others have since been added to the list.

Even if all the microorganisms contaminating a spacecraft are killed, it may not be enough to avoid a false-positive result. Modern life-detection equipment can spot tiny amounts of carbon-containing compounds - enough for it to be fooled by dead bacteria left behind after cleaning and sterilization, or even the organic chemicals used in cleaning. "This is the biggest challenge," says John Rummel, planetary protection officer at NASA's headquarters in Washington.

The NASA and Beagle 2 teams are reluctant to discuss the details of the methods they are working on, as each is keen to commer-

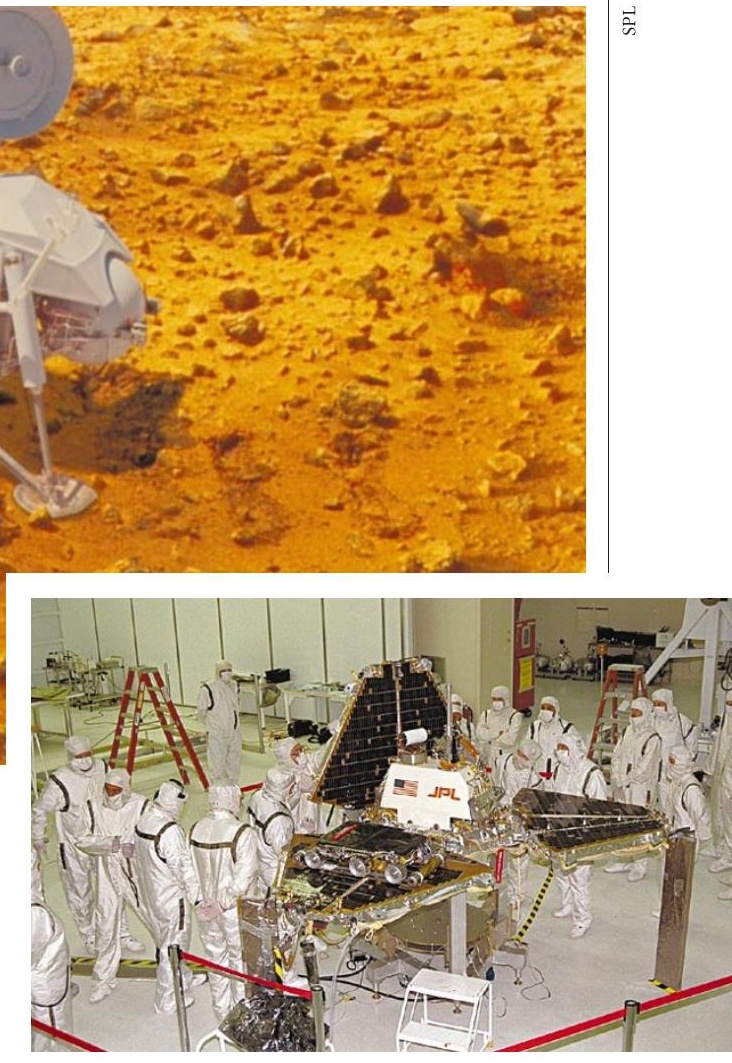

cialize any techniques they develop. Both groups are also wary of potential criticisms of their methods, and say they will not publish them until they are finalized.

But the teams confirm that they are interested in a technique used to disinfect surgical equipment in hospitals. Devices are sterilized in a vacuum chamber into which a sample of hydrogen peroxide is injected. This vaporizes, and a high-voltage electric field is then used to strip the electrons from the gaseous atoms, leaving behind a plasma containing highly reactive atomic nuclei. These react with and destroy any biological molecules on the surface of the device, without unduly damaging the equipment itself.

Mark Sims, Beagle 2's project manager at the University of Leicester, says his team will definitely be using plasma sterilization on some of Beagle's metal parts, but other areas will have to be treated in different ways. Parts of the craft that come into direct contact with samples may also be heat-treated, he says.

The teams are also testing alternative ways of cleaning the probes before sterilization. The traditional technique — wiping with 
alcohol - can compound the problem. On aluminium, for example, this bursts cells and glues their innards to the surface.

NASA is currently experimenting with alternatives, including ultrapure water and the water-based cleaning fluids that the semiconductor industry is developing to replace the chlorofluorocarbons used to clean circuit boards. So far, no single method has proved adequate for aluminium - a potential problem as the metal is a common component of spacecraft.

The nylon brushes used to scrub surfaces before wiping with alcohol can also cause difficulties. To a mass spectrometer — standard equipment for detecting the molecular signatures of life - the bonds between nitrogen atoms in nylon could easily be confused with those in amines, the building blocks of proteins. NASA has now taken the advice of David White, an environmental microbiologist at Oak Ridge National Laboratory in Tennessee, who suggested using polypropylene instead, which should not confuse the analysis.

The teams are also working on techniques
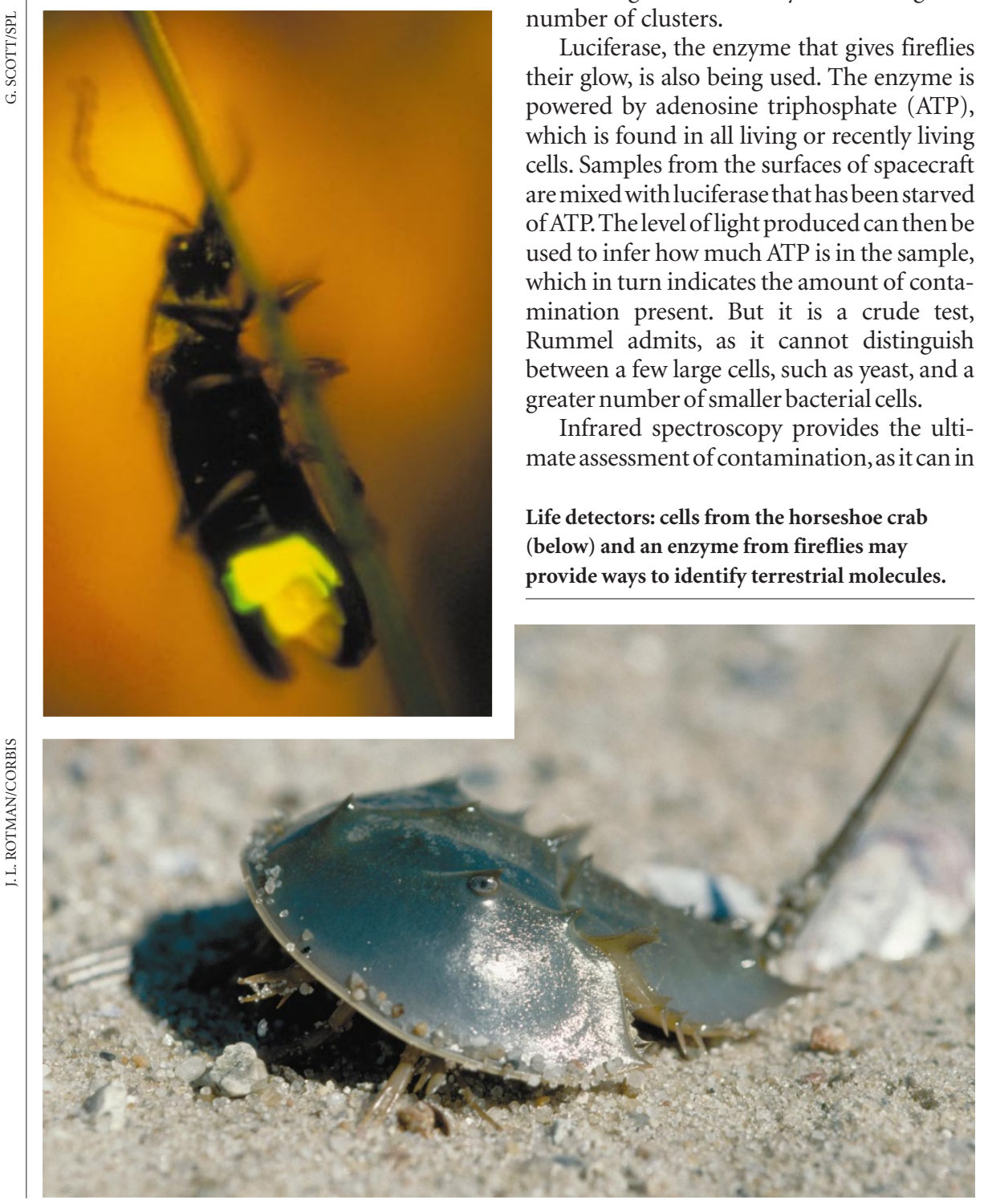

Life detectors: cells from the horseshoe crab (below) and an enzyme from fireflies may provide ways to identify terrestrial molecules. principle detect individual molecules by analysing the way they interact with light. Spectroscopy can only be used to study tiny samples, but the Beagle 2 team plans to use the technique to assess contamination on the parts of the craft that will come into direct contact with martian samples.

The NASA and Beagle 2 teams will also monitor contamination in their spacecraft-assembly facilities, in order to provide a list of potential microbial

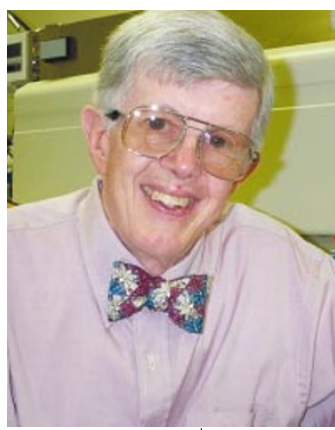

David White: advising NASA on microbial contamination. stowaways. If they do end up detecting a possible martian microbe, the inventory will act as a background against which the signal can be compared. "We definitely want to be able to recognize terrestrial life that has hitched a ride there," says Max Coleman, a geologist at the University of Reading in England who is advising NASA on its detection techniques.

\section{Bugs in the system}

Compiling this inventory is "an awful job", says White. Numerous bacteria in the facilities cannot be cultured and identified, a problem NASA is hoping to solve by looking for traces of RNA from their ribosomes, cellular structures involved in the synthesis of proteins. Researchers have identified ribosomal RNA sequences for many types of bacterium which have never been cultured. The technique could provide the most thorough inventory of potential bacterial stowaways, but it is proving difficult to implement. "The bugs haven't been worked out yet," concedes Rummel. The British team behind Beagle 2 is likely to face similar difficulties when it starts assembling its spacecraft next July.

When the full protocols are finalized, Rummel says that NASA will go public with its methods. But this may not happen before the 2007 missions - too late for the Beagle 2 team to benefit from them. "We have tried to pick their brains and have had some discussions," says Sims. "But like us, they are developing new procedures.” Full details of the Beagle 2 proposals are contained within a planetary protection plan that has just been submitted to ESA, and which the Beagle 2 team insists must remain confidential.

Some experts, such as White, argue that the secrecy surrounding the two teams' work could threaten the reliability of the life-detection experiments. Ultimately, the intense desire to avoid a false positive may provide the motivation for all those involved to begin discussing their work more openly. As Coleman says: "The possibility of subsequent embarrassment is too great."

Tom Clarke is a member of Nature's science writing team. 